\title{
A Study on the Role of Government and Private Health Expenditures on Iran Economic Growth in 1968 to 2012
}

\author{
Ali Kazemi ${ }^{1}$ \\ ${ }^{1}$ MA in Economic Sciences, Islamic Azad University, Science and Research Branch, Iran \\ Correspondence: Ali Kazemi, MA in Economic Sciences, Islamic Azad University, Science and Research Branch, \\ Iran. E-mail: esfehani.mohamad3@gmail.com
}

Received: July 27, 2016

Accepted: August 18, 2016

Online Published: September 3, 2016

doi:10.5539/mas.v10n12p213

URL: http://dx.doi.org/10.5539/mas.v10n12p213

\begin{abstract}
The aim of current study is to investigate the effects of government and private health expenditure on Iran economic growth in 1968 to 2012. Identifying the influencing factors on economic growth is necessary and deeper researches are required. Based on conducted researches, the influencing factors on economic growth includehuman capital, a factor which has been effective on economic growth more than any other factors and besides this, physical and technological and work force can lead to increase gross domestic product of the country. In accomplished researches the effect of government and private expenditures on Iran economic growth has been investigated, based on this the variable of health expenditures has entered growth patterns which has a positive significant effect on Iran economic growth and econometric techniques and tools have been used in order to calculate it. Ultimately, it answers this questions that if there is a significant relationship between health expenditures and economic growth.

All concerned tension coefficients are in accordance with research hypothesis, GDP tension compared to LED is equal to 1.26 so if life expectancy at birth in Iran increases for one percent (almost 1.26 year) then economic growth will increase as 2.38 percent, LET tension or life expectancy at birth in Iran compared to HEG or government final consumption expenditure on healthcare is equal to $15 \%$ and shows that with 1 percent of increase in government final consumption expenditure on healthcare, life expectancy will increase almost $15 \%$, LET tension in Iran compared to HEP or final consumption expenditure of households on healthcare is equal to $8 \%$ and shows that with 1 percent of increase in HEP, life expectancy will increase almost 0.08 percent. Government final consumption expenditure tension in healthcare is almost twice the tension of final consumption expenditures of the country in healthcare and represents that government expenditures is efficient compared to private section in order to increase life expectancy at birth.
\end{abstract}

Keywords: economic growth, government and private health expenditures, life expectancy, the productivity of work force

\section{Introduction}

Today health has an important role in countries' economic growth process. One of the reasons for improving health situation of Iranian citizens in recent decades has been appropriate activity of government and private that has caused promotion of human development in Iran. So that some of countries which are standard in terms of human development (HPI) have acceptable economic development and government health expenditure like government expenditure in education and training promotes the quality of human resources and causes increasing life expectancy and society's people life span. It increases tending to investment and capital and causes faster economic growth. In another word increasing government health expenditure causes promoting public health of the society and is effective on economic growth directly through health capital accumulation and its impact on human capital. There are generally three approaches in investigating the relationship between health and economic growth; the effects of economic growth will be investigated on health in first approach, the effect of health on economic growth will be investigated in the second one, third approach will investigate mutual effects of health and economic growth. This study is going to investigate and analyze health effects on economic growth. This study is aimed to investigate the effects of government and private health expenditures on economic growth in Iran. Based on this, the question which is raised is that what effects government health expenditure has on Iran economic growth. In accordance with this question, this hypothesis is discussed that 
government health expenditure has positive effect on Iran economic growth.

Human resource is one of the most important production factors that through participation of production prominently in this field, lack of human capital or lack of efficient use of that cause even the existence of vast oil revenues doesn't lead to real development because of this, investment on human resources and the process of human capital is considered as main core of economic growth. Health Organization of continent America has also concluded in investigating Latin American countries and the Caribbean Sea that one year of increase in life expectancy will lead to one percent of increase in gross domestic product in future 15 years. Therefore in industrial west countries, governments and people notice investment on human resources and increasing the efficiency of workforce. Investment on human resources has comprehensive and deep effects on economic growth.

\section{Research Plan}

This research is applied type and its method is causal using econometric techniques and combining time series data, E VIEWS software has been used in estimating research model.

\section{Collecting data method}

1) Statistics Center of Iran Calendar

2) Economic Report of the Central Bank and the World Health Organization

\section{Research main problem}

a) Do healthcare expenditures affect Iran GDP (gross domestic product)?

b) Do government and private healthcare expenditures affect Iran economic growth?

\section{Research hypotheses}

a) Investigating the effects of government and private healthcare expenditures on Iran economic growth through considering accomplished health expenditures in growth pattern

b) Investigating the role of investment in promoting health of human resource in the form of economic theories and the effect of these expenditures on Iran economic growth

c) Investigating the role of investment in health of society on gross domestic product in the form of growth patterns

\section{Main Hypothesis}

a) Government and private healthcare expenditures have positive and significant effect on Iran economic growth.

b) The effects of government healthcare expenditures are more than private healthcare expenditures on Iran economic growth.

\section{Theoretic Principles of Healthcare Effect on Economic Variables}

\subsection{Economic Growth and Development}

A scientific definition of economic growth is obviously important in terms of methodology and it cannot be defined based on tastes, impressions or personal demands. It can be said briefly:

- Firstly, economic development is an objective meaning not a concept

- Secondly, economic development is historical not conceptual

So for better recognition of this concept, two methods can be used.

In first method that investigates objective study of the development phenomenon, world countries are divided into two main groups. Some of countries are called developed economically and the other ones undeveloped and some of countries that have better situation than undeveloped ones but meanwhile their economic situation isn't as good as developed ones. Since in developing countries and especially Iran, major part of products is work-based that is in the process of producing goods and services, work factor is used more than investment factor so improving health situation causes improving health situation of workforce as well as increasing workforce efficiency and ultimately economic growth so improving health and nutrition is one of important factors in forming human capitals and finally economic growth.

The researches which have been accomplished by Professor Robert Fogel indicate that reducing mortality which has been occurred in 200 past years in Europe has positive and direct relationship with increasing calorie intake 
in people diet or improving nutrition status and promoting public health and medical technology. According to him, increasing calorie for workforce has significant effect on per capita income growth rate of Britain and France in 200 recent years. He perceived this point in his investigations that appropriate health and nutrition lonely have been able to improve 20 to 30 percent of England economic growth during 1780 to 1979.

Economic expenditures of preventable diseases when are added to other expenditures of curing diseases and illnesses will get a significant amount of money. In fact diseases reduce people per capita income and prevent their economic growth. On the other hand disease may deteriorate poor families because such families consume a part of their income or capital for providing curing expenditures. Econometric studies of Bloom and Sachez, 1998 show that more than half of African economies growth retardation compared to economic growth in Southeast Asia is related to the factors such as diseases and geographical features and the prevalence of infectious diseases like malaria, AIDS, etc. has been one of important factors in reducing economic growth of those countries. For example it has been shown that the prevalence of infectious diseases like malaria can reduce annual economic growth rate for one percent.

\subsection{Health and Human Capitals}

Since economists have got the importance of human resources, a significant attention was given to different methods in order to improve economic conditions and within this human capitals importance has been especially emphasized. The subject of human capital which first had been discussed by balanced growth theorists was gradually noticed by other economy scholars. So that a group named human capitals theorists was appeared among economic development and growth scholars. Schultz who is one of prominent scholars of human resources has emphasized on the importance of human aspect in growth and development in all his books such as "human wealth and economic growth". In this book, he investigated different aspects such as the cases below;

The accurate perception of how economic growth is obtained is very important. Many discussions about this have been concentrated around materialistic subject against spiritual values up to now that is because the capital is defined by good or goods that can be reproduced and capital on human framework hasn't been emphasized. Tending to economic growth is for example stated in work and investment while this attitude is wrong and development key is human not materialistic resources. Ha has concluded in his investigation on America economic growth during 1929-53:

During these years, real national income of America has got almost twice that is a growth near 3 percent in a year. Within this very increase, the resources of workforce around 17 percent and the value of materialistic resources that is total saving of capital is high around 43 percent and if these resources are weighted averagely, totally an average growth as annually 1.2 percent compared to 3 percent real national income growth has been obtained. Now the question is that how the rest of growth can be justified and interpreted? An unknown factor which has caused economic growth during these years is increasing the saving of human wealth. The source of fast economic development in developed world has been done more through human capital developments and changes than physical and materialistic capital so how human capital is formed should be emphasized more for surviving undeveloped countries from poverty because the thing which is ignored in development and growth patterns of these societies after the second world war is the importance of human and human capital that this ignorance has caused undeveloped world not to take advantage of physical and materialistic capitals that have created and formed.

Schultz showed in a historical investigation that the reason of underdevelopment of the countries with vast rich natural resources is their human capital poverty because of this enrichment of capital and human resources of these societies that is enrichment of education expertise, hoping for better life, spiritual and physical progress of men, women and kids should be development agenda of those countries.

\subsection{Health and Economic Growth}

The studies that have been done about growth in macro economy level can be divided into three general groups.

- The studies which have been accomplished based on growth accounting

- The studies which have been accomplished based on exogenous growth models

- The studies which have been accomplished based on endogenous growth models

The studies that have been done recently on economic growth are mainly related to endogenous growth models and the subject of developing human capital and its role in economic growth has been noticed seriously. Some of main points of endogenous economic growth models and their testing include:

- Key role of human capital and its accumulation in the rate of long-term economic growth so that the 
existence of human capital in production function, neutralizes the zone of descending return and so leads to long-term per capita growth in the conditions of lacking exogenous technology development

- The effect of knowledge and the existence of that in investments as well as promoting and expanding knowledge and technology so that this factor is efficient and effective for eliminating descending return of capital;

- Lack of capital descending return assumption and instead of that considering the assumption of ascending return or fixed return to scale in production function in which the justifier is considering physical and human capital as well as knowledge infrastructure;

- And finally expanding and developing human capital leads to growth and expansion of production factors and return growth of production factors or in another word increasing efficiency is considered as important factor of economic growth.

\section{AK Model}

General mode of these models is as $\mathrm{Y}=\mathrm{AK}$. A represent an effective factor on technology and $\mathrm{K}$ also includes physical and human capital. In these models the capital return is always considered fixed and there isn't descending return. This is because of some side effects that are created by hidden technology in capital and neutralize tending descending return. Considering the mentioned assumption optimum behavior of families and firms are taken into consideration and provides a framework for endogenous growth. Considering the introduction of general equation of endogenous models $\mathrm{AK}$, the behavior of families, firms can be investigated as balancing and dynamicity condition of model.

\subsection{Growth Models of $R \& D$}

In recent theories, the innovation and invention which is the result of $\mathrm{R}$ and $\mathrm{D}$ is called endogenous technology development. In theories above, there are two assumptions below about return growth.

First assumption: according to Arrow who believes knowledge and benefits of its returns will be obtained from investment and production, so it can be assumed that increasing in the capital of firm parallel leads to increase in knowledge existence $A_{i}$ of that company. Therefore learning process with producing services and goods will act through investment in each firm.

Second assumption: the knowledge of each firm is a public good that other companies can achieve that with zero capital. In another word knowledge is disseminated to all over the world. This assumption says that changing in technology of each company depends on learning level or education in whole economy and therefore it will relatively lead to change in total capital that is $\mathrm{K}$.

\subsection{Health and Endogenous Model}

\subsubsection{Lucas Model}

One of studies which have been accomplished about the relationship between health and economic growth in the framework of endogenous growth models is young growth model of Muyskan and Joan and Advian Van Zan, 2003 that will be investigated in this part. These two researchers used Lucas model in order to investigate the effect of health of people on economic growth and added health variable to his model.

Initial Lucas model can be summarized as below:

$$
Y=A \cdot\left((1-w) e \cdot P^{\alpha} \cdot K^{1-\alpha}\right.
$$

That $\mathrm{Y}$ is production rate, a fixed parameter of efficacy, $\mathrm{P}$ population size, $\mathrm{K}$ the saving of human capital and $\mathrm{e}$ is average efficiency for each worker while $1-\mathrm{w}$ is the fraction of work time allocated to the final product number. As result $w$ includes a fraction of time for each worker that is allocated knowledge accumulation. 1- $\alpha$ is little tension of capital towards production. A and $\alpha$ are also fixed parameters and $\mathrm{w}$ is a fixed variable in sustainable mode and $\mathrm{K}$ will increase in sustainable mode with fixed and appropriate rates of growth.

\subsubsection{Bloom, Canaing and Sevilla Model}

This model is derived from Bloom, Canaing and Sevilla 2001 which used health effect on economic growth in their research. Main assumption of this model is:

- Economic growth is derived from two growth sources of production inputs including physical capital, workforce and human capital and growth in total factor productivity (TFP);

- Production is a function of inputs and technology 
Production function is:

$$
Y=A K^{\alpha} L^{\beta} e^{\phi_{1}+\phi_{2} \exp +\phi_{3} \exp ^{2}+\phi_{4} h}
$$

Y shows production or GDP, A represents TFP and K physical capital and L is also workforce. Human capital includes three components of the mean of education years or $\mathrm{S}$, the mean of work experience or exp, work experience square or $\exp ^{2}$ and health or $\mathrm{h}$ and $\mathrm{h}$ with life expectancy will be identified as an appropriate successor.

In equation above, it is mentioned that production logarithm depends on education level, experience, experience square and health status that are in accordance with the findings in knowledge level.

If get a logarithm from total production function, we will obtain an equation from production logarithm in the county $i$ at the time $t$ :

$$
y_{i t}=a_{i t}+\alpha k_{i t}+\beta l_{i t}+\phi_{1} s_{i t}+\phi_{2} \exp _{i t}+\phi_{3} \exp _{i t}{ }^{2}+\phi_{4} h_{i t}
$$

That $y_{i t}, k_{i t}, l_{i t}$ is logarithm $Y_{i t}, K_{i t}, L_{i t}$ but $a_{i t}$ which is representative for TFP in the country i at the time t, when we estimate equation won't be appeared as error sentence therefore TFP will be:

$a_{i t}=a_{i t} *+v_{i t} \rightarrow v_{i t}=\rho v_{i, t-1}+\varepsilon_{i t}$

$0<\rho<1$ is and $\varepsilon_{i t}$ is also random shock. Each country has a balanced level for TFP in long-term that is assumed $a_{i t} *$ here. Real TFP is shown as $a_{i t}$ that is deviated from its balanced value by random difference $v_{i t}$ and consists of systematic and special components. Systematic difference which is appeared as $\rho v_{i t, t-1}$ will be downsized during the time and special components are introduced as $\mathcal{E}_{i t}$. A special simple case which has been spread in studies is the claim that $a_{i t} *$ is equal for whole country that is $a_{i t} *=a_{t} *$ $v_{i t}$ also shows country i deviation from public level of technology in the world at the time t. this deviation may be fixed but during the time, this country's TFP with the rate of $1-\rho$ will be convergent to world level that $1-\rho$ shows the speed of technology spreading.

Balanced TFP may be considered different among countries, in this case $a_{i t} *$ is a function of geography which is considered by a percentage of county's areas that are located in tropical areas and the criterion of political institutions quality because on one hand because of creating obstacle for dissemination of agricultural technology from temperate regions to the tropics as well as lack of advantage in producing food and spread of endemic diseases, tropics are recently introduced as a geographical factor which prevents growth creation. On the other hand the quality of political institutions can justify economic growth because strong political institutions may provide social stability, public services effectively and strengthening private contracts that are required for growth.

\subsubsection{Adding Surveillance Activities to Model}

Unfortunately curing all unhealthy or patient people is impossible. We assume here that unhealthy people or patients require caring and will enjoy these kinds of cares practically. In each second of the time this work requires some expenditures in using health sources for workforce that would fits the number of people who are 
patient or inactive and its fitness factor is X. assume that these sources are fraction of $\mathrm{u}$ from society's healthy population; as result we will have:

$$
\text { u.h.P }=X .(1-h) . P \Rightarrow u=X .(1-h(v)) / h(v)
$$

\section{The Effects of Population Changes on Economic Growth}

The reason of investigating burden of aging population in terms of endogenous growth is that basically such these effects are important but while using, standards tools for these methods are usually ignored. Jacobzone et al 2000 for example used a simple extrapolation scheme for achieving the estimation of health expenditure share from GDP and in order to this the current share of the resulting relative increase over time is multiplied in dependence ration compared to its current value, the numerator of dependence ration is a direct representative of predicted increase in health demand while the denominator of this fraction is an explicit and direct marker of predicted increase rate based on studied economic production. Nevertheless this kind of mechanical plan is too much optimistic and faulty for extrapolation (especially in long-term) because increasing the ratio of dependency through increasing people's life span and moderations that will be brought toward this may act as a deterrent to economic growth.

Since care activities don't apparently have sensitivity toward technical changes that increase workforce power, the law and model will be strongly established. The necessity of required cares of elderly while they require these kinds of cares will lead to the way of inevitability to change the distribution of labor time to the advantage of healthcare and as results will increase the aspects of economic growth significantly, the problems which are derived from aging the population of society. This point that such aspects of economic growth can be really important and considerable will be directly the result of growth process relative sensitivity to obtained changes in demographic and disease cognition parameters on one hand and natural importance of demographic expected changes in future that ultimately will create some changes in the rate of people dependency. Nevertheless in this level we only can consider the existence of a mode which is compatible in decision making trend about medical expenditures with economic growth perspective based on public balance but we can't defend this theory completely numerically or empirically although as it was mentioned before there are many practical and environmental evidences to confirm that.

\subsection{Time Series}

Time series is one of the most important statistical data which is used in empirical analysis. It has been always assumed in researches that time series is stationary and otherwise common statistical tests which are based on t, F, Chi2 and similar ones will be doubted. On the other hand if the variables of time series aren't stationary, recursive regression might occur. In these types of regressions meanwhile that there might be no significant relationship among model variables, the coefficient determination $\left(\mathrm{R}^{2}\right)$ may be too high and make researcher to have wrong inferences about the rate of relationship among variables. This problem is because that both time series (dependent variable and explanatory ones) show a severe tendency toward time (ascending and descending movements) and so very high $\mathrm{R}^{2}$ which can be seen is derived from the existence of time variable not because of real relationship among variables.

\subsection{Unit Root Test}

Unit root test is one of the most common tests that are used today for diagnosing the stationary of time series process. The basis of unit root tests is that when a process is a regression of first degree $\rho=1\left(y_{t}=\rho y_{t-1}+u_{t}\right)$, in that case series $\mathrm{y}_{\mathrm{t}}$ is non-stationary. Therefore if coefficient of $\rho$ is estimated through Ordinary Least Squares Method and its 1 equality is tested, stationary or non-stationary of a time series process can be proved. The problem here is that proposed t by OLS method with the accuracy of the assumption $\rho=1$ ordinary isn't ordinary even in large samples with $t$ (this problem exists about statistic $F$ ) and as result critical quantities of $t$ cannot be used for this test.

\subsection{Stationary Test of Gross Domestic Product (GDPC)}

According to the trend which is mentioned, ADF test was done on the variable of gross domestic product; this variable wasn't stationary and became stationary with one time of differencing. This done so that proposed ADF should be bigger than critical values in confidence levels that the results show that because of ADF being smaller than critical values, hypothesis $\mathrm{H}_{0}$ cannot be rejected based on variable non-stationary in confidence level of $99 \%$ and therefore this variable is non-stationary and is bigger than critical values with one time of differencing statistic ADF and zero hypothesis based on this variable non-stationary will be rejected in confidence level of $99 \%$ and therefore this variable is I (1). 


\subsection{Stationary Test of Life Expectancy (LET)}

About the variable of non-confidence life expectancy, the results of variable stationary are in the difference of first time because doing this test in variable level have proposed the results based on ADF being smaller than critical values and zero hypothesis based on non-stationary of variable in confidence level of $99 \%$ won't be rejected therefore through doing this test again in the difference of first level, it was observed that ADF statistic is bigger than critical values and $\mathrm{H}_{0}$ hypothesis which indicates variable non-stationary will be rejected. Based on findings, this variable is also I (1).

\subsection{Stationary Test of HEP Variable}

Stationary test was done for HEP and this variable also in level had less ADF values than critical ones therefore through one time of differencing, this variable got stationed as well and the values of ADF were proposed bigger than critical values that zero hypothesis based on non-stationary HEP variable in confidence level of $99 \%$ was rejected and so that this variable is also I (1).

\subsection{Vector Auto Regression Models (VAR)}

When we want to investigate the behavior of some time series variables, mutual relationships of these variables in the form of a system of simultaneous equations model is required to be noticed. In these equations, there might be variables delay also that in this case it will be so called dynamic system of simultaneous equations model. In such model, some of variables are considered endogenous and some of them exogenous (pre-predicted). Therefore before estimating such model, it is better to ensure if the equations are recognizable but the important issue is that classifying these variables into two groups of endogenous and exogenous is optional so this issue was severely criticized by Simes (1980). According to him if there is really simultaneity among a set of model variables, all variables should be looked at equally and prejudgment about each one is endogenous or exogenous won't be correct. In this case he introduced VAR models. This model doesn't have any exogenous variables and all of variables in this model are endogenous.

\subsection{Determining the Length of Lag}

The first issue in VAR models is determining the length of lag that in this equation, some criteria can be applied in model. There are two valid criteria for determining the length of lag or selecting the rank of model which include AIC and SC that are defined as below:

$$
\begin{aligned}
& \text { (Akaike info criterion) } \mathrm{AIC}=-21 / \mathrm{T}+2 \mathrm{n} / \mathrm{T} \\
& \text { (Schwarz criterion) } \mathrm{SC}=21 / \mathrm{T}+\mathrm{n} \log (\mathrm{T}) / \mathrm{T}
\end{aligned}
$$

Here $\mathrm{T}$ is sample volume and $\mathrm{n}=\mathrm{k}(\mathrm{d}+\mathrm{pk})$ is the total number of all estimated parameters in VAR model. It is noticeable that the length of lags should be selected so that these two criteria get minimized.

Determining Appropriate Lag Length in Model

As it was mentioned before, for determining optimum lag in model, different indicators are used. The best one for this model was first lag therefore this lag was selected as the best lag length of model.

\subsection{Vector Error Correction Model (VECM)}

A vector error correction model is in fact a suitable VAR that is used for cointegration time series.

The part of cointegration is considered as part of error correction because deviation from long-term balance will be gradually corrected through short-term compliance of a series part. As the simplest mode, we consider a bivariate system with a cointegration equation without interruption. Cointegration equation will be as follows:

$$
y_{2, t}=\beta y_{1, t}
$$

And model VEC in accordance with it is:

$$
\begin{aligned}
& \Delta y_{1, t}=\alpha_{1}\left(y_{2, t-1}-y_{1, t-1}\right)+\varepsilon_{1, t} \\
& \Delta y_{2, t}=\alpha_{2}\left(y_{2, t-1}-y_{1, t-1}\right)+\varepsilon_{2, t}
\end{aligned}
$$

In this simple model, only right variable is part of error correction. This part is zero; in long-term therefore if y1and y2 get distance from long-term balance, error correction part won't be zero. The speed of adopt secure I of 
endogenous variable toward balance is measured by $\alpha_{i}$.

Since this model is being used for cointegration series "Johansen" test integration should be first done and the number of long-term relations should be recognized. In fact this information is necessary for model specification. In fact this model relates variables' short-term behavior to their long-term balanced values and shows that how lack of balance related to variables long term balance relationships affect their short-term dynamic changes.

When in method VAR, modeling is done based on differencing first time of stationary variables, some of long-term information will be removed within this (of course ignoring this information will be serious problem when available variables in system have long-term relationships). In case two variables are cointegration, estimating their long-term relationship through time series data will be easier and there won't be any problems such as recursive regression. Of course when such model is applied the assumption is the existence of a stationary long term relationship and the changes of two variables and the type of their relationship in short-term are ignored. Of course balance mode happens rarely and the main reason is that economic firms cannot react to new information immediately and moderate their behavior or decisions. Even if the information is accurate and complete, the value of a dependent variable such as $Y_{t}$ in equation not only is affected by explanatory variable $\left(X_{t}\right)$ but also is affected by $X_{t-1}$. Since $Y_{t}$ is formed in reaction to the past and present changes, for avoiding very long lags of $X_{t}$ in right side of equation, the lag values of $Y_{t}$ will be also added to the model as explanatory variable.

\section{Cointegration}

Cointegration is one of the important subjects in time series discussions. Economic concept of cointegration is that when two or more time series are related to each other based on theoretical principles to form a long-term balance relationship, although these time series had been random (non-stationary) but follow each other over time well so that their difference is stationary. The problem of non-stationary of time series variables of a regression model can be removed through differencing but using variables differencing, we lose valuable information about the level of variables and nothing can be done in order to maintain long-term information about the level of variables.

To eliminate this problem, cointegration test should be applied to the model to achieve a regression without worrying about falsehood based on the level of time series variables.

Generally if two time series are cointegration from different ranks, their linear combination, cointegration is higher rank than their total rank that is if one is I (1) and the other I (2), their linear combination will be I (2). Therefore liner combination of two processes in I (1) is usually I (1). However there might be a special linear combination that if we combine those two series, the combination will be I (0). In this case these two series will be called cointegration.

\section{Conclusion}

In studies related to economic growth and development, many prominent scientists of economy such as Harod, Dumar, Arthur Luis, Celvin Clark, Tinn Bergen, and Hirschman and ... have vast attempts in order to discover problems and state different aspects of economic growth and development of different countries. International organizations, national governments and many economic institutions also had paid adequate attention to related problems in economic growth and development in different countries. The results of related studies which have been published and available for everybody as valuable articles about analyzing economic growth and necessary solutions for economic progress of developing countries, related problems to forming capital or investment in different economic sections for economic growth and development. The result of all these studies and researches is that today economic development is vital goal of all nations and driving spirit of all people and because of these taken policies, is very important in economic growth and development in cultural, social, political and economic programming of all countries generally and developing ones specifically.

According to all economists the most important and main factor in countries' economic growth is investment and the difference in their thoughts and ideas are hidden in how they invest.

Therefore since the main issue in economic growth and development is hidden in investment now this question is raised that in which economic section, investment can be main derive in economic activities and move investment in other economic sections in another word. In order to answer the questions which is raised, economists have proposed different attitudes and each one of them has published valuable articles. It was tried in this research to investigate the effect of society health on economic growth of the country in two aspects of theoretic and applied principles and propose an important aspect of available problems in order to speed accessing the developmental and plan goals of the country. All coefficients of concerned coefficients are in 
accordance with the research hypotheses.

GDP tension compared to LED is equal to 1.26 so if life expectancy at birth in Iran increases for one percent (almost 1.26 year) then economic growth will increase as 2.38 percent, LET tension or life expectancy at birth in Iran compared to HEG or government final consumption expenditure on healthcare is equal to $15 \%$ and shows that with 1 percent of increase in government final consumption expenditure on healthcare, life expectancy will increase almost 15\%, LET tension in Iran compared to HEP or final consumption expenditure of households on healthcare is equal to $8 \%$ and shows that with 1 percent of increase in HEP, life expectancy will increase almost 0.08 percent. Government final consumption expenditure tension in healthcare is almost twice the tension of final consumption expenditures of the country in healthcare and represents that government expenditures is efficient compared to private section in order to increase life expectancy at birth.

\subsection{Recommendations}

Considering the obtained results, policies and recommendations below can be suggested to planners of Management and Planning Organization of the country as well as health authorities.

Considering that investment in healthcare field isn't noticed that much by private section and on the other hand government resources cannot meet the needs of health section of the country so through motivating and financial encouragements and giving facilities at lower rates to investors of private section, government should invest in the field of healthcare.

Considering the results of this research the effect of increasing life expectancy on increasing human resources productivity will lead to economic growth, the programs of society health promotion are recommended to be noticed in macro planning of the country.

Accomplished studies show that the effectiveness of government section is more than private one so the expenditures of hospital cares should be allocated to initial health area which is more effective.

\subsection{Recommendations for future research}

1) Estimating the increase of society's people's intelligence quotient and its effect on economic growth

2) Investigating the role of increasing life expectancy and its effect on economic growth

3) Estimating the damages of human resources and its effect on economic growth

\section{References}

Aasefzadeh, S. (2003). Principles of Health Economics. Qazvin, publications of Medical Sciences University, p. 43.

Bidram, R. (2002). Evies along with econometrics. Tehran, Manshour Bahrevari publications, p. 110. In the case of private sector investment variable due to structural breaks in this variable, Phillips-perron unit root test is used.

Branson, W. H. (1997). The theory of macroeconomic policies. Translated by Dr. Abbas Shakeri, first and second version, Ney publications.

Health Care in Asia. (1992). Comparative Study of Cost and Financing World Bank. Washington D.C. p. 58.

Karimi, I. (2002). A review on the problems of the health sector in Iran. Jahane Eghtesad Newspaper, 2491.

Marzban, H. (2012). The role of health and education in the economic growth of some of the developing countries. Thesis. Information Center of Central Bank of the Islamic Republic of Iran

Mojtahed, A., \& Javadipour, S. (2004). Studying the effect of health expenditure on economic growth (Case study: Selected developing countries). Economic Research of Iran Journal, Summer(19).

Romer, D. (2004). Advanced Macroeconomics. First version, growth theory, translated by Dr. MAhdi Taghavi. Scientific Research University (1st Ed.).

\section{Copyrights}

Copyright for this article is retained by the author(s), with first publication rights granted to the journal.

This is an open-access article distributed under the terms and conditions of the Creative Commons Attribution license (http://creativecommons.org/licenses/by/4.0/). 